\title{
Editorial
}

\section{Non-invasive early diagnosis of oral cavity malignancies}

\author{
Jon Sudbø \\ Department of Medical Oncology and Radiotherapy, The Norwegian Radium Hospital, Montebello, 0310 Oslo, \\ Norway
}

Received 19 May 2003

Accepted 20 May 2003

Oral cancer is a multistep, multipathway and multifocal process extending over a period of 10-20 years, where most manifest carcinomas are assumed to be preceeded by readily detectable visible changes of the oral mucosa $[3,4]$. It is not known to which extent carcinomas may arise from clinically normal oral mucosa, but reliable molecular markers indicate that cancer may arise from lesions that by traditional histological assessment are assumed to be without any malignant potential [6,7]. However, oral carcinogenesis most likely represents a field process, with multiple clones developing independently, in a metachronous manner [1,2,5]. Conceivably, aggressive cells clones that have not yet given rise to visible lesions could subsequently give rise to subsequent carcinomas.

Currently, there are no reliable non-invasive methods for screening for oral cancer in patients with a high-risk behaviour for oral cancer, but with clinically normal appearing oral mucosa. However, risk of oral cancer can be assessed by measuring DNA content in cells of the mucosal lining in patients with visible lesions. In this issue of the journal, Remmerbach and colleagues present a case study of 4 patients, from which they obtained cytobrushings to look for genetic changes relevant for development of oral squamous cell carcinomas. Notably, the initially performed biopsies did not indicate malignant transition. Brush biopsies were obtained and smears of these were investigated cytologically after Papanicolaou staining. After cytological assessment, cells were restained with Feulgen and measurement of DNA content was performed by image cytometry. Although the results will need to be reproduced by other independent groups, this limited case study demonstrates the proof of principle that significant genetic changes in epithelial linings can be detected by non-invasive methods.

The incidence rate of oral cancer is increasing. Today, a substantial portion of new cases is diagnosed at an advanced stage of disease, which contributes to the poor prognosis of this group of patients. Early detection of subclinical lesions makes possible an early intervention, e.g., by chemoprevention in this patients group [8]. Demonstrating that person at high risk may be identified by non-invasive methods is an important contribution that opens for opportunistic screening of high-risk persons.

Molecular risk markers to identify persons at high risk of cancer $(>50$ percent cancer risk within a time span of 3-4 years) can only be feasible in a screening setting if the procedures related to the work-up are not associated with undue strain on persons at risk. In this respect, the study by Remmerbach marks an interesting advance.

\section{References}

[1] J. Califano, W.H. Westra, W. Koch, G. Meininger, A. Reed, L. Yip, J.O. Boyle, F. Lonardo and D. Sidransky, Unknown primary head and neck squamous cell carcinoma: molecular identification of the site of origin, J. Natl. Cancer Inst. 91 (1999), 599-604.

[2] J. Califano, W.H. Westra, G. Meininger, R. Corio, W.M. Koch and D. Sidransky, Genetic progression and clonal relationship of recurrent premalignant head and neck lesions, Clin. Cancer Res. 6 (2000), 347-352. 
[3] A. Forastiere, W. Koch, A. Trotti and D. Sidransky, Head and neck cancer, N. Engl. J. Med. 345 (2001), 1890-1900.

[4] S.M. Lippman and W.K. Hong, Cancer prevention science and practice, Cancer Res. 62 (2002), 5119-5125.

[5] D.P. Slaughter, H.W. Southwick and W. Smejkal, Field cancerization in oral stratified squamous epithelium: Clinical implications of multicentric origin, Cancer 6 (1953), 963-968.

[6] J. Sudbø, W. Kildal, B. Risberg, H.S. Koppang, H.E. Danielsen and A. Reith, DNA content as a prognostic marker in patients with oral leukoplakias, N. Engl. J. Med. 344 (2001), 12701278
[7] J. Sudbø, T. Ried, M. Bryne, W. Kildal, H.E. Danielsen and A. Reith, Abnormal DNA content predicts the occurence of carcinomas in non-dysplastic oral white patches, Oral Oncol. 37 (2001), 558-565.

[8] J. Sudbø, A. Ristimaki, J.E. Sondresen, W. Kildal, M. Boysen, H.S. Koppang et al., Cyclooxygenase-2 (COX-2) expression in high-risk premalignant oral lesions, Oral Oncol. 39(5) (2003), 497-505. 


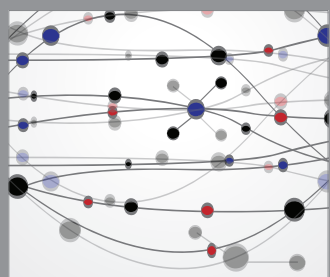

The Scientific World Journal
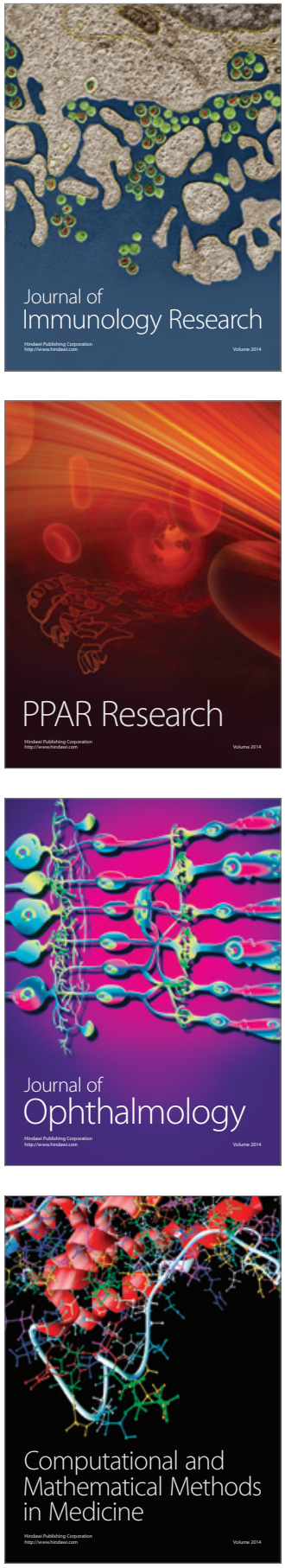

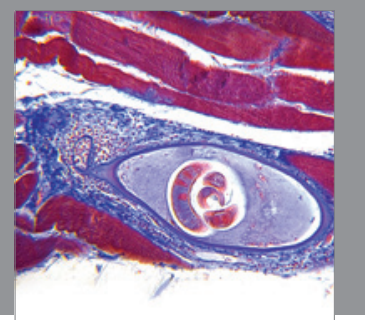

Gastroenterology

Research and Practice
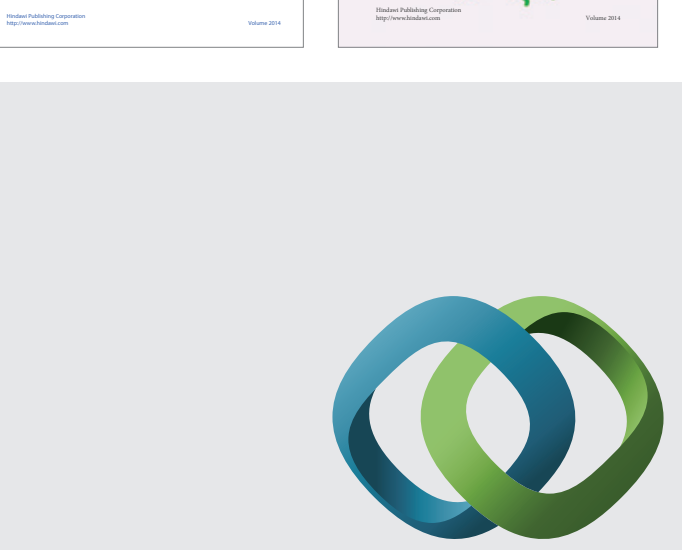

\section{Hindawi}

Submit your manuscripts at

http://www.hindawi.com
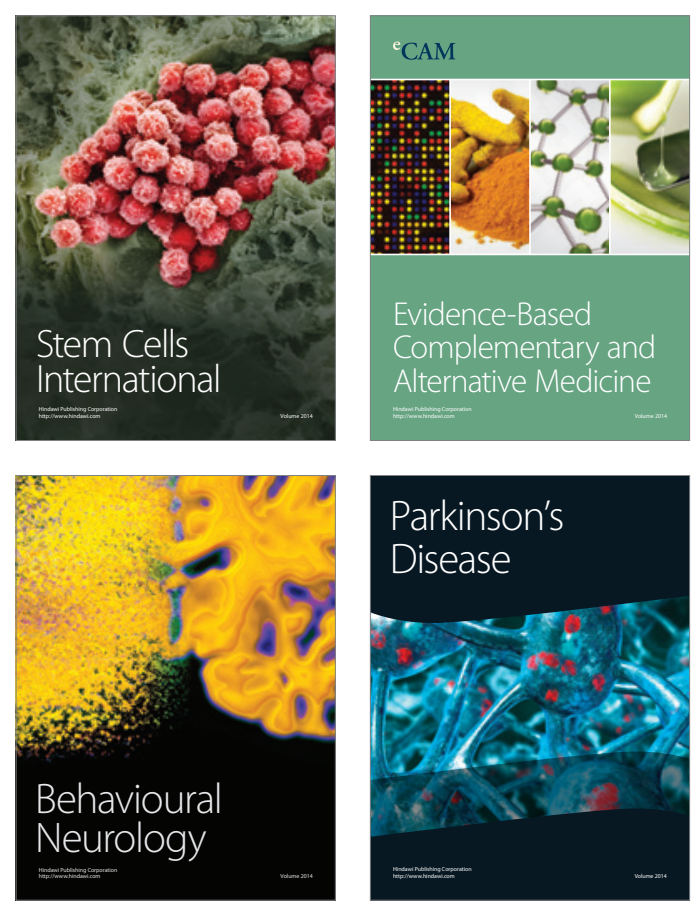

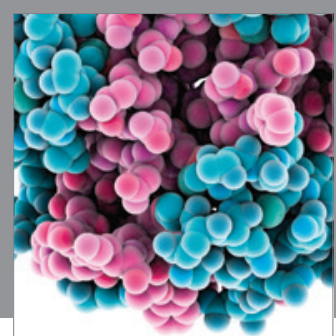

Journal of
Diabetes Research

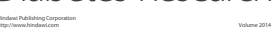

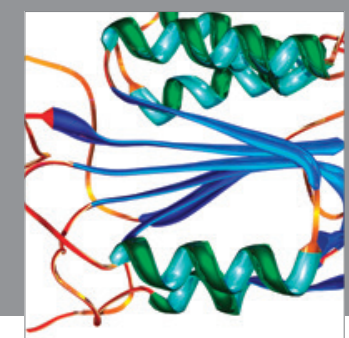

Disease Markers
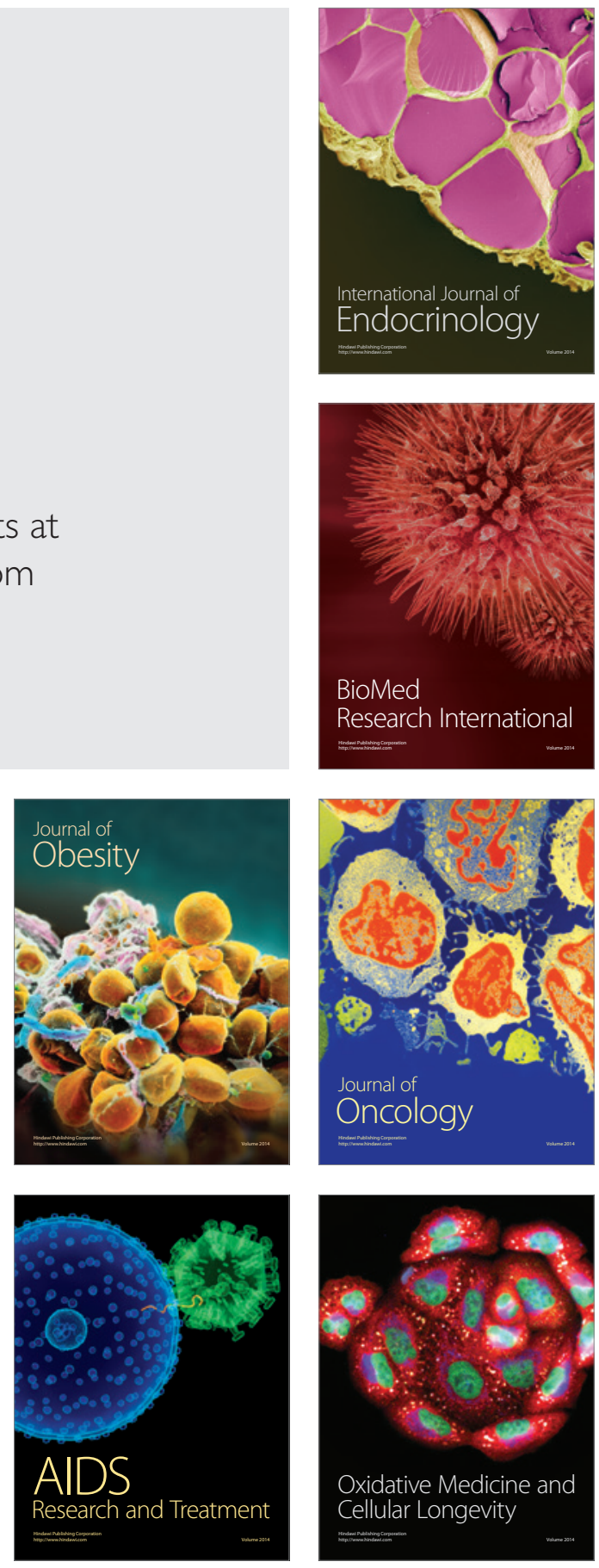